\title{
Colon Cancer: A Clinician's Perspective in 2019
}

\author{
Monjur Ahmed
}

\begin{abstract}
Colon cancer is a common preventable cancer. With the adoption of widespread colon cancer screening in the developed countries, the incidence and mortality of colon cancer have decreased in the targeted population. But unfortunately, the incidence and mortality of colorectal cancer (CRC) have been increasing over the last 25 years in the young adults below the age of 50 . There is disparity in benefit, i.e. reduction in risk of death between right-sided and left-sided colon cancer by screening colonoscopy. The reason could be multifactorial and various measures have been taken to decrease this disparity. Although most of the screened populations are average risk individuals, a minority of the population have various risk factors for developing colon cancer and need to follow specific colon cancer screening guidelines. Gene mutations (adenomatous polyposis coli (APC), deleted in colon cancer (DCC), K-ras, p53, B-Raf proto-oncogene serine/threonine kinase (BRAF), mismatch repair genes) and microsatellite instability lead to the development of colon cancer. Although various non-invasive methods of colon cancer screening are now available, colonoscopy remains the gold standard of colon cancer screening and adenoma detection rate is now being used as the quality metrics in screening colonoscopy. Although Multi-Society Task Force (MSTF) and American College of Physicians (ACP) recommend initiating screening colonoscopy at age 50 years in all individuals except African Americans who should begin screening colonoscopy at age 45 years, the American Cancer Society (ACS) recommends initiating screening colonoscopy at age 45 years in all individuals irrespective of race and ethnicity. Low-volume split-dose prep has been found to be as effective as high-volume split-dose prep and more tolerable to patients with increased compliance. Boston bowel preparation scale is recommended to measure the quality of colon cleansing. CRC is curative if it is diagnosed at an early stage but various palliative treatment options (endoscopic, oncologic and surgical) are available in advanced stages of this cancer. Adequate number of lymph node assessment during surgery is essential in accurate staging of CRC. Checkpoint inhibitors have been found to have dramatic response and durable clinical benefit in dMMR/MSI-H metastatic CRC. Different genetic and immune-oncologic research trials are ongoing for early detection and better management of CRC.
\end{abstract}

Keywords: Colon cancer; Colorectal cancer; Screening for colorec-

Manuscript submitted November 3, 2019, accepted December 3, 2019

132 South 10th Street, Main Building, Suite 468, Philadelphia, PA 19107, USA.Email: monjur.ahmed@jefferson.edu

doi: https://doi.org/10.14740/gr1239 tal cancer; Management of colorectal cancer; Colon cancer in young adults

\section{Introduction}

When we think about common preventable cancers, first thing comes to our mind is colon cancer or CRC. In fact, CRC is now the third most common cancer diagnosis among men and women in the United States of America [1]. With the widespread availability of colonoscopy, CRC is increasingly being diagnosed now-a-days, sometimes at an early stage and sometimes at an advanced stage. According to the World Health Organization (WHO), in 2018, globally 1.80 million new cases of CRC were diagnosed and 862,000 patients died from CRC [2]. In USA, approximately, 145,600 cases of CRC are diagnosed annually. Out of them 1,014,200 cases are colon cancers and the rest are rectal cancers [3]. Generally, in CRC, 71\% are in the colon and $29 \%$ in the rectum. About 50,000 patients die from CRC annually in USA. During the period of 2008 2014 , the incidence of CRC decreased slightly in men $(2.2 \%$ per year) but remained stable in women. The mortality rate from CRC also decreased by $1.8 \%$ per year among men and $1.4 \%$ per year among women from 1999 to 2015 [4]. There are various screening programs recommended by American Cancer Society (ACS), Multi-Society Task Force (MSTF) and American College of Physicians (ACP). Although most (about $70 \%$ ) of the CRC occurs in the average risk individuals (sporadic), up to $25 \%$ of cases occur in patients with family history of CRC, and about $10 \%$ of cases occur in hereditary colorectal cancer syndromes [5]. Now we have much better understanding in the pathogenesis of sporadic and hereditary CRC on the basis of molecular research [6]. In metastatic CRC, targeted therapies and checkpoint inhibitors are chosen according to the status of K-ras mutations, mismatch repair (MMR) gene defect and microsatellite instability (MSI). In this review, risk factors for developing CRC, the screening recommendations of both average-risk and high- risk individuals, cancerogenesis, clinical manifestations and available treatments of CRC in 2019 will be discussed.

\section{Risk Factors for the CRC}

The chance of developing $\mathrm{CRC}$ can be increased by environmental factors and/or genetic factors. The various risk factors for developing CRC include age above 50, low socioeconomic 
Table 1. CRC Screening Recommendations by MSTF in 2017

\begin{abstract}
Average-risk individuals
First tier tests: colonoscopy every 10 years or annual FIT. Colonoscopy should be offered first. If colonoscopy is refused, annual FIT.

Second tier tests: CT colonography every 5 years or FIT-fecal DNA test every 3 years or flexible sigmoidoscopy every 5 to 10 years.

Third tier test: capsule colonoscopy every 5 years.

Septin9 serum assay: not recommended for screening CRC.
\end{abstract}

\section{Family history of CRC}

Persons with one first-degree relative of CRC or documented advanced adenoma diagnosed $<60$ years or two first-degree relatives with those findings at any age screening colonoscopy every 5 years beginning 10 years before the age at diagnosis of youngest relative or age 40 , whichever is earlier.

Persons with a single first-degree relative diagnosed at $\geq 60$ years with CRC or an advanced adenoma - average risk screening options at age 40 years.

CRC: colorectal cancer; MSTF: Multi-Society Task Force; FIT: fecal immunochemical test; CT: computed tomography.

class, overweight and obesity, sedentary life style, tobacco smoking, heavy alcohol intake, low-fiber and high fat diet, consumption of red meat, processed meat and burnt or charred meat, diabetes mellitus and insulin resistance, acromegaly, renal transplantation with long-term immunosuppression, long-term androgen deprivation therapy, personal or family history of CRC or colorectal adenoma, long-standing inflammatory bowel disease (IBD), familial adenomatous polyposis (FAP), mutated MMR gene syndromes like hereditary nonpolyposis colorectal cancer (HNPCC) or Lynch syndrome and Muir-Torre syndrome, hamartomatous polyposis syndromes like Peutz-Jeghers syndrome, Cowden syndrome and Juvenile polyposis syndrome, and non-inherited polyposis syndromes like serrated polyposis syndrome (SPS) and Cronkhite-Canada syndrome. We are also noticing that the incidence of CRC has been increasing in young adults (YA) in their 30s and 40s over the last 25 years in high income countries (United States, United Kingdom, Denmark, Norway, Canada, Australia and New Zealand), whereas it has been decreasing in adults after age 50. But the absolute incidence of CRC among YA remains much lower than among adults aged $\geq 50$ [7]. YA generally present with late stage CRC (mainly left sided and rectal) as they ignore their symptoms most of the time. Smoking, alcohol intake, obesity, metabolic syndrome, male, black, Asians and family history of $\mathrm{CRC}$ have been found to be risk factors for early development of CRC. Thirty-five percent of YA with CRC have some sort of genetic mutation, whereas $3-5 \%$ of all $\mathrm{CRC}$ cases have genetic mutation. So genetic studies should be considered in YA with CRC even without any family history of colon cancer [8].

\section{Screening Programs}

MSTF which represents American College of Gastroenterology (ACG), American Gastroenterology Association (AGA) and American Society of Gastrointestinal Endoscopy updated the CRC screening in 2017 as shown in Table 1 [9]. In November 2019, ACP updated the CRC screening recommendation in average-risk individuals between the age of 50 and 75 years as shown in Table 2 [10].

ACS recommended last year that average-risk individuals start regular CRC screening at age 45. AGA supported this new recommendation for earlier CRC screening. Tests recommended by ACS for CRC screening are two broad categories [11]: visual/structural tests and stool-based tests. Visual/structural tests include colonoscopy every 10 years, CT colonography every 5 years and flexible sigmoidoscopy every 5 years. Stool-based tests include fecal immunochemical test (FIT or iFOBT) every year, high-sensitivity guaiac-based fecal occult blood test (gFOBT) every year and multitarget stool DNA (MT-sDNA or FIT-DNA) test every 3 years. Cologuard is the only stool DNA test available approved by the United States Food and Drug Administration (FDA). It incorporates mutant KRAS, and $\beta$-actin, methylated BMP3 and NDRG4 gene promoter regions and fecal immunochemical test for human hemoglobin. iFOBT, gFOBT and FIT-DNA tests are homebased, and patients collect stool samples using a kit and mail the kit to a laboratory for testing. Colonoscopy is indicated if any of the stool-based tests or flexible sigmoidoscopy or CT colonography becomes positive [12]. Sometimes, patients present with FIT positivity after normal colonoscopy. In an observational population-based study, the incidence of developing CRC was $0.4 \%$ over a period of 4.7 years [13]. It is the author's opinion not to do FIT after a high quality normal colonoscopy as FIT can be positive due to other lesions in the gastrointestinal tract.

In 2014, capsule colonoscopy was approved by the United States FDA to detect colon polyp only for patients with incomplete colonoscopy [14]. Methylated SEPT9 DNA is shed into the blood from colon cancer and it can be detected by polymerase chain reaction (PCR) in the blood. In a meta-analysis, methylated SEPT9 had a sensitivity of $71 \%$ and specificity of $92 \%$ in detecting CRC [15]. Methylated SEPT9 assay

Table 2. CRC Screening Recommendations by ACP in 2019

\begin{tabular}{l} 
Average-risk individuals \\
FIT or gFOBT every 2 years. \\
Colonoscopy every 10 years. \\
Flexible sigmoidoscopy every 10 years plus FIT every 2 years. \\
\hline
\end{tabular}

CRC: colorectal cancer; ACP: American College of Physicians; FIT: fecal immunochemical test; gFOBT: guaiac-based fecal occult blood test. 
(Epi proColon) is the first blood test approved by the FDA for CRC screening in April 2016. Although colonoscopy is the gold standard test for detecting colon polyps and cancer, it is not perfect. Interval cancer (CRC diagnosed after a screening or surveillance colonoscopy in which no CRC was found and before the date of next recommended colonoscopy) was found in $6 \%$ of all patients with CRC within 6 to 60 months of a colonoscopy in a population-based study. The interval cancers were more in the right colon, at an early stage with lower risk of death, and associated with higher rate of adenoma and family history of CRC $[16,17]$.

How much benefit can be gained by strictly following these tests? FOBT if performed annually can reduce the number of death due to CRC by $15-33 \%$ [18]. Stool DNA test is more sensitive than FOBT and can detect greater proportion of colorectal neoplasia [19]. Regular screening with flexible sigmoidoscopy can lower the mortality from distal CRC by $50 \%$ [20]. Screening colonoscopy may reduce the CRC mortality by $60-70 \%$ [21]. It is not yet known whether CT colonography can reduce $\mathrm{CRC}$ mortality.

\section{Screening Colonoscopy}

The decreased CRC incidence and mortality are probably due to the adoption of colon cancer screening, removal of adenomatous colon polyps, early detection of colon cancer and availability of better treatment. Doubeni et al conducted a nested case-control study and found that screening colonoscopy was associated with a $75 \%$ reduction in risk of death for left-sided colon/rectal cancer and a $65 \%$ reduction for right-sided colon cancer [22]. The disparity in benefit between the two sides is multifactorial. Missed polyp or lesion in the right colon is an important factor. This could be due to inadequate cleaning of right colon, incomplete colonoscopy or difficulty in visualizing polyps on the proximal aspect of colonic folds by standard colonoscopy. Biologic factor includes difficulty in visualizing right colonic flat serrated adenoma containing BRAF V600E that can develop microsatellite unstable right-sided colon cancer. Some studies showed that there could be an increased incidence of right-sided colon cancer in females [23] and elderly population [24]. Different measures have been taken to improve detection of right-sided colon polyp. These include use of split dose colon preparation, high definition colonoscopy (1,080 pixels), double-right colon examination (DRCE), retroflexion of colonoscope in right colon, Endo cuffs, transparent caps, Endo rings, G-Eye balloon endoscope and Third Eye panoramic device.

Adenoma detection rate (ADR) is now considered as the national benchmark on quality of screening colonoscopy and primary indicator for decreasing $\mathrm{CRC}$ through the use of screening colonoscopy. ADR is measured by dividing the number of screening colonoscopies in which one or more adenomas are detected by the total number of screening colonoscopies. ADR does not count the total number of adenomas detected [25]. High ADR percentages have been found to be associated with low colon cancer cases. If the ADR increases by $1 \%$, a patient's risk of developing colon cancer over the next year decreases by $3 \%$. ADR is inversely associated with development of interval $\mathrm{CRC}$, advanced stage interval cancer and fatal interval cancer [26]. The recommended ADR is $20 \%$ or more in females, $30 \%$ or more in males and $25 \%$ or more on an average [27].

Of the colon surface, $13.4 \%$ is not visualized during standard colonoscopy as suggested by a simulation study that used CT colonography. ADR is higher with high-definition colonoscopy compared with standard definition colonoscopy. Wide angle colonoscopes are also now being used for screening colonoscopy. A study done by Rex et al did not find any significant difference in missing polyp using standard colonoscope with $140^{\circ}$ field of view and wide angle colonoscope with $170^{\circ}$ field of view [28]. Different measures like split-dose preparation, retroflexion of the colonoscope in the right colon, DRCE and adjunctive accessories like Endo cuffs, transparent caps, Endo rings, G-Eye balloon and Third Eye panoramic device are being used to improve right-sided colon polyp detection rate [29].

\section{Penetrability of Colonoscopy in General Popu- lation}

Screening colonoscopy is an effective means of detecting and removing pre-cancerous lesions in the colon. But acceptance of having this test done in the target population is not very high. Many individuals consider colonoscopy as a cumbersome test probably due to the hassle of going through colon cleansing, procedure related pain and complications. Cost is also an important factor. One in three target patients (age 50 to 75) who (about 38 million people) need screening colonoscopy are still not getting the procedure done. In 2012, 6.3 million screening colonoscopies were done in the United States. CRC screening in the target population increased from $58 \%$ in 2013 to $63 \%$ in 2015 [30]. Screening colonoscopy rate is increasing steadily because of different medical society guidelines, instructions by the primary care physicians, national media coverage, digital marketing and social media.

Many patients do not tolerate high-volume colon cleansing regimens. A systematic review of 17 randomized controlled trials showed that low-volume, split-dose regimens were as effective as high-volume, split-dose regimens in colon cleansing with better tolerance and superior compliance [31]. Patients should be given easy-to-understand colonoscopy prep instructions to improve compliance. Adequate cleansing of colon mucosa is essential for higher detection of colon polyps. Quality of colon cleansing is now-a-days measured by the Boston bowel preparation scale (BBPS) - a nine-point standardized and validated bowel cleanliness rating scale as shown in Table 3 [32]. The right colon, i.e. cecum plus ascending colon, the transverse colon including the hepatic and splenic flexures, and the left colon, i.e. descending colon, sigmoid colon and rectum are assessed for cleanliness. Each of them gets 0 to 3 points and as a result, total BBPS score can be 0 to 9 . It is recommended to repeat colonoscopy within a year if BBPS score is $<5$ and if the BBPS score is $\geq 7$, repeat colonoscopy should be done at regular intervals [33]. 
Table 3. BBPS Scores

\begin{tabular}{ll}
\hline Score & Colon cleanliness \\
\hline 0 & $\begin{array}{l}\text { Unprepared colon segment with mucosa not seen due to solid stool that cannot be cleared. } \\
1\end{array}$ \\
$\begin{array}{l}\text { Portion of mucosa of the colon segment seen, but other areas of the colon segment not well seen due to staining, residual stool and/or } \\
\text { opaque liquid. }\end{array}$ \\
$\begin{array}{l}\text { Minor amount of residual staining, small fragments of stool and/or opaque liquid, but mucosa of colon segment seen well. } \\
3\end{array} \quad$ Entire mucosa of colon segment seen well with no residual staining, small fragments of stool or opaque liquid.
\end{tabular}

BBPS: Boston bowel preparation scale.

\section{High-Risk Individuals for CRC}

Risk for the development of CRC can be average or high. Average-risk individuals are those who do not have any polyposis syndrome, hereditary colorectal cancer syndrome, long-standing IBD and personal or family history of CRC or advanced colorectal adenoma. Most of the average-risk individuals develop $\mathrm{CRC}$ after 50 years of age. Individuals with high risk of CRC develop CRC at an early age and as a result, it is essential for them to follow a specific screening and surveillance program. They are as follows: 1) Family history of CRC: Single first-degree relative with $\mathrm{CRC}$ or advanced adenoma (adenoma $\geq 1 \mathrm{~cm}$ in size, or with high-grade dysplasia or villous histology) diagnosed below the age of 60 years or two first-degree relatives with $\mathrm{CRC}$ or advanced adenomas at any age. ACG recommends screening colonoscopy every 5 years beginning at age 40 or 10 years earlier than the youngest index case in the family [34]. 2) Patients with classical (germline mutation of APC gene) should be screened for CRC by annual colonoscopy or flexible sigmoidoscopy until the time of colectomy. The average age of onset of polyposis is 16 years and the average age of development of CRC is 39 years [35]. The time of colectomy depends on patients' symptoms, size and number of adenomas, presence of cancer or high-grade dysplasia. Elective colectomy is generally done in late teens or early twenties if there is less number $(<10)$ of adenoma or small-sized $(<5 \mathrm{~mm})$ adenomas. Early colectomy should be done if the patient is symptomatic with gastrointestinal bleeding, there are many 6 to $10 \mathrm{~mm}$ polyps which cannot be cleared by endoscopic polypectomy or there is marked increase in number of colon polyps in consecutive colonoscopies [36, 37]. Urgent colectomy should be considered if there is adenoma with high-grade dysplasia, or suspected or documented CRC. Following surgery, ongoing surveillance should be continued as there is a chance of developing adenoma or adenocarcinoma in the ileal pouch, rectal cuff or in the ileostomy site [38, 39]). 3) Patients with attenuated FAP (germline mutation of APC gene near its 3' end or 5' end) develop100 or less adenomatous colon polyps (predominantly right-sided) at age 20 to 25 with a tendency to spare the rectum and the average age of development of CRC is 55 years. Colon cancer screening should start at age 20 to 25 and there is no upper limit of stopping the surveillance. Regular screening esophagogastroduodenoscopy (EGD) should also be done to look for gastric and duodenal adenoma [40]. 4) HNPCC: Patients who fulfill the Amsterdam or Bethesda criteria for HNPCC should have their CRC tested for
MSI, i.e. variability in number of nucleotides in repeat DNA sequences within the tumor cells and MMR proteins by immunohistochemical staining. If the tests become positive, patients should get genetic testing for HNPCC. All the family members with positive genetic testing should get screening colonoscopy every 2 years starting age 20 to 25 until age 40, then annually [41]. 5) SPS: It is the most common polyposis syndrome. The prevalence is $0.033 \%$, i.e. 1 in 3,000. According to WHO, clinical criteria for SPS include: 1) at least five serrated polyps proximal to the sigmoid colon, with two or more of those being $\geq 1 \mathrm{~cm} ; 2$ ) any number of serrated polyp proximal to the sigmoid colon in a person who has a first-degree relative with SPS; or 3) $\geq 20$ serrated polyps of any size distributed throughout the colon [42]. In SPS, the cumulative incidence of $\mathrm{CRC}$ is $7 \%$ in 5 years under endoscopic surveillance [43]. The US MSTF on CRC recommends surveillance colonoscopy annually in all patients with SPS [44]. 6) Long-standing IBD: The incidence of CRC is six times more in IBD patients than that in general population. CRC is responsible for $10-15 \%$ of death in patients with IBD [45]. The risk factors for developing $\mathrm{CRC}$ in IBD include disease duration, extent of colitis, severity of colitis, presence of primary sclerosing colitis (PSC), orthotopic liver transplantation for PSC and family history of IBD [46]. The risk of developing CRC in ulcerative colitis (UC) and Crohn's disease (CD) is equivalent [47]. In case of UC, screening colonoscopy is recommended 8 to 10 years after the diagnosis of pancolitis, extensive colitis and left-sided colitis. The follow-up surveillance colonoscopy should be done every 1 to 2 years depending on the presence or absence of dysplasia. Proctitis and proctosigmoiditis do not pose increased risk of developing CRC [48]. Patients with personal diagnosis of PSC and family history of CRC should undergo screening colonoscopy at the time of diagnosis and then every year. In patients with Crohn's colitis involving at least one-third of the colon, the screening colonoscopy and surveillance colonoscopy protocol are same as in patients with UC. As the presence of active colitis has substantial impact on the diagnosis of dysplasia, screening colonoscopy and surveillance colonoscopy should be done when the disease is on remission [49]. Traditionally, white light colonoscopy with four quadrant random biopsies are taken every $10 \mathrm{~cm}$ starting from the cecum to the rectum as well as targeted biopsies are taken if there is any mucosal abnormalities. Recently chromoendoscopy or high definition colonoscopy is advocated to detect dysplasia in patients with IBD [50]. Chromoendoscopy using methylene blue or indigo carmine spray on the colon mucosa can detect fine mucosal changes and dysplasia 2 - 3 times more than conventional 
Table 4. Screening for $\mathrm{CRC}$ in High-Risk Individuals

\begin{tabular}{ll}
\hline High-risk individuals for CRC & Recommendations \\
$\begin{array}{l}\text { 1. Family history: single first-degree relative with CRC or advanced } \\
\text { adenoma diagnosed below the age of } 60 \text { years or two first-degree } \\
\text { relatives with CRC or advanced adenomas at any age. }\end{array}$ & $\begin{array}{l}\text { Screening colonoscopy every } 5 \text { years beginning at age } 40 \text { or } 10 \\
\text { years earlier than the youngest index case in the family. }\end{array}$ \\
$\begin{array}{ll}\text { 2. Classical FAP } & \text { Annual colonoscopy or flexible sigmoidoscopy starting at age } 12 \\
\text { to } 14 \text { years until the time of colectomy. } & \text { Colon cancer screening should start at age } 20 \text { to } 25 \text { and there is } \\
\text { no upper limit of stopping the surveillance. }\end{array}$ \\
$\begin{array}{ll}\text { 4. HNPCC } & \begin{array}{l}\text { All the family members with positive genetic testing should get } \\
\text { screening colonoscopy every } 2 \text { years starting age } 20 \text { to } 25 \text { until } \\
\text { age } 40, \text { then annually. } \\
\text { 5. SPS }\end{array} \\
\text { Surveillance colonoscopy annually. } \\
\text { Screening colonoscopy is recommended } 8 \text { to } 10 \text { years after the } \\
\text { diagnosis of pan-ulcerative colitis, extensive ulcerative colitis and } \\
\text { left-sided ulcerative colitis as well as Crohn's colitis involving at } \\
\text { least one third of the colon. }\end{array}$ \\
\hline
\end{tabular}

CRC: colorectal cancer; FAP: familial adenomatous polyposis; HNPCC: hereditary non-polyposis colorectal cancer; SPS: serrated polyposis syndrome; IBD: inflammatory bowel disease.

white light colonoscopy [51, 52].

The high-risk individuals for $\mathrm{CRC}$ with current recommendations for screening and surveillance are summarized in Table 4.

\section{Development of CRC}

There are sequential multistep mutational processes in the development of CRC. Seventy percent of CRC arises from adenoma-carcinoma sequence seen in sporadic adenoma and FAP [53] and 30\% arises from other pathways which include MMR gene defect seen in Lynch syndrome, BRAF mutation seen in sessile serrated polyps and base-excision repair (BER) gene defect seen in MYH-associated polyposis syndrome [54]. In adenoma-carcinoma sequence, loss of function of tumor suppressor genes: adenomatous polyposis coli (APC) gene on chromosome 5q, deleted in colon cancer (DCC) gene on chromosome $18 \mathrm{q}$ and p53 gene on chromosome 17p and activation of oncogene KRAS on chromosome 12p lead to the formation of CRC. Loss of function of APC gene is considered to be the critical first step in the adenoma-carcinoma sequence. Loss of function of DCC gene leads to late stage of adenoma progression, whereas loss of p53 gene occurs at the terminal stage of adenoma-carcinoma sequence. KRAS oncogene activation occurs in $35-45 \%$ of CRC. It is associated with increased aggressiveness of CRC, decreased responsiveness to select chemotherapeutic agents particularly anti-EGFR (epidermal growth factor) agents in metastatic colon cancer, and poor survival [55]. MMR genes are involved in correcting the mistakes made during DNA replication. MMR-deficient cells have many DNA mutations which may lead to MSI and cancer. Sporadic CRC with somatic MMR gene mutations and MSI constitutes $12-15 \%$ of total CRC in USA. They occur mostly in Caucasians, middle-aged to older population without any family history of CRC, almost always in the right colon and carry a relatively good prognosis. Aberrant DNA methylation of $\mathrm{CpG}$ islands, i.e. $\mathrm{CpG}$ island methylator phenotype (CIMP), is widely distributed in CRC. CIMP-associated methylation of MLH1 leads to sporadic cases of MMR deficiency. Germline mutations in the MMR genes (hMSH2, hMLH1, hPMS1 and hPMS2) occur in HNPCC and they account for 3-6\% of total CRC in USA [56]. BRAF (B-Raf proto-oncogene serine/threonine kinase) gene mutation (valine-to-glutamate change at the residue $600-\mathrm{V} 600 \mathrm{E}$ ) is found in $10 \%$ of CRC. Sessile serrated adenoma (SSA) and traditional serrated adenoma (TSA) are developed due to BRAF mutation. CRC due to BRAF mutation are generally right-sided, occurring in old age, more recurrent in females and associated with MSI. BRAF-mutated $\mathrm{CRC}$ with MSI is generally associated with a better prognosis but proximal right-sided $\mathrm{CRC}$ carries a bad prognosis [57]. Almost all cases of BRAF-mutated CRC are CIMP-positive [58]. So CIMP-positive tumors are characteristic of tumors arising from serrated adenoma. About 50\% of CIMP-positive tumors are microsatellite unstable. Twenty percent to $30 \%$ of all CRC are CIMP-positive and $10-12 \%$ of all CRC are CIMP-positive and microsatellite unstable.

\section{Treatment of CRC}

CRC is not only preventable but it is also one of the most treatable cancers if it can be diagnosed early. Treatment depends on the stage of the disease. TNM staging system and Dukes Class for CRC with 5-year survival are shown in Table 5.

Stage I CRC is treated by surgical resection of the tumor and the local lymph nodes. During surgery, examination of adequate number of lymph nodes is essential for correct staging of CRC. According to American Joint Commission on Cancer and the National Quality Forum, harvesting of at least 12 lymph nodes is considered as a quality indicator of $\mathrm{CRC}$ resection [59]. 
Table 5. TNM Staging System and Dukes Class for CRC With 5-Year Survival

\begin{tabular}{llll}
\hline Stage & Code & 5-year survival & Dukes class \\
\hline 0 & TisN0M0 & 100 & \\
I & T1N0M0 & 100 & A \\
& T2N0M0 & 90 & B1 \\
II & T3N0M0 & 75 & B2 \\
& T4N0M0 & 30 & \\
III & Any TN1M0 & 60 & C \\
& Any TN2M & 30 & \\
IV & Any T, any N, M1 & 3 & D \\
\hline
\end{tabular}

Primary tumor (T): Tis - carcinoma in situ; T1 - tumor invades submucosa; T3 - tumor invades through muscularis propria into subserosal; T4 - tumor directly invades other organs or structures, and/or perforates visceral peritoneum. Regional lymph nodes $(\mathrm{N})$ : N0 - no regional lymph node metastasis; $\mathrm{N} 1$ - metastasis in one to three regional lymph nodes; N2 - metastasis in four or more regional lymph nodes. Distant metastasis (M): M0 - no metastasis; M1 - distant metastasis. CRC: colorectal cancer.

Malignant polyps are T1 lesions in which cancer cells have invaded the muscularis mucosae into the submucosa. They account for $12 \%$ of polyps in polypectomy series [60]. They may appear benign looking endoscopically. When the histology comes back as a malignant polyp, we need to make a decision whether endoscopic resection is adequate or patient needs endoscopic mucosal resection (EMR), endoscopic submucosal dissection (ESD) or segmental colonic resection. Pedunculated (Ip in Paris classification) malignant polyp is considered cured with snare polypectomy if the resection margin is $2 \mathrm{~mm}$ or more, the histology is not poorly differentiated and there is no lymphovascular involvement [61]. Segmental resection of colon is recommended if the resection margin is less than $2 \mathrm{~mm}$, the histology is poorly differentiated and there is lymphovascular involvement. But sessile (Is in Paris classification) malignant polyp is not cured with snare polypectomy and segmental resection of colon is recommended. But if the patient is a poor surgical candidate, EMR (for $2 \mathrm{~cm}$ or smaller lesion with superficial submucosal invasion) or ESD (for $>2$ $\mathrm{cm}$ lesion with superficial submucosal invasion or $<2 \mathrm{~cm}$ lesion with significant submucosal fibrosis making EMR impossible) should be considered. Depth of invasion of cancer cells into the colon polyp is associated with lymph node metastasis. In case of pedunculated malignant polyp, level 4 invasion (i.e. cancer cells invading the submucosa of colon wall below the level of stalk as per Haggitt classification) is associated with lymph node metastasis up to $27 \%$ [62]. In case of sessile polyp, cancer cells invasion into the lower third of submucosa is associated with lymph node metastasis up to $23 \%$ [63]. So ESD is contraindicated in deep submucosal invasion of cancer cells. Stage II CRC is treated by surgery alone and routine use of adjuvant chemotherapy is not recommended. The European Society of Medical Oncology (ESMO) (last updated in 2013) recommended adjuvant chemotherapy in the presence of any of the high risk features which included poorly differentiated cancer, lymphovascular invasion, perineural invasion, report of $<12$ lymph nodes, bowel obstruction, localized perforation and positive margins [64]. The adjuvant chemotherapy should include 6 months course of one of the following chemotherapy regimens: 5-flurouracil (FU) with leucovorin (LV), capecitabine, or combination of 5-FU with LV and oxaliplatin (FOLFOX) or capecitabine and oxaliplatin (Capeox). Stage III CRC is treated by curative surgical resection of the tumor followed by adjuvant chemotherapy which includes six cycles of FOLFOX or Capex [65]. In USA, stage II and stage III rectal cancers are treated by neoadjuvant chemoradiation (infusion of 5-FU with LV plus 4,500 to 5,040 cGy of radiation therapy) over a period of 5 to 6 weeks followed by surgery (low anterior resection or abdominal perineal resection) 6 to 10 weeks after completion of chemoradiation [66]. Stage IV colon cancer can be managed by monotherapy or a combination of chemotherapy, biologic targeted therapy, immunotherapy/checkpoint inhibitor therapy, palliative surgery, radiotherapy and radiofrequency ablation. Before planning the treatment modality, the location of primary CRC and extent of the disease, tumor MSI, KRAS/NRAS and BRAF mutation status, patient's comorbidities, prior treatment history, goals of treatment and patient's preferences should be considered [67]. The treatment is palliative for most patients and the main aim is to maintain quality of life and prolong overall survival. Some of the common chemotherapeutic agents used in stage IV CRC are FOLFIRI (5-FU, LV and irinotecan), FOLFOX (5-FU, LV and oxaliplatin), CAPIRI (capecitabine and irinotecan), CAPOX (capecitabine and oxaliplatin), 5-FU with LV, irinotecan, capecitabine and trifluridine plus tipiracil (Lonsurf). Targeted therapy is generally given in combination with chemotherapy. The type of targeted therapy depends on whether the CRC is KRAS mutation-positive or is KRAS mutation-negative (wild-type). The targeted therapy includes: 1) bevacizumab (monoclonal antibodies against vascular endothelial growth factor (VEGF)); 2) ramucirumab (monoclonal antibody against vascular endothelial growth factor receptor (VEGFR)); 3) cetuximab and panitumumab (monoclonal antibody against epidermal growth factor receptor (EGFR)); 4) regorafenib (angiogenic, stromal and oncogenic kinase inhibitor) and 5) aflibercept (VEGF A inhibitor and placental growth factor inhibitor). Bevacizumab, ramucirumab, regorafenib and aflibercept are angiogenesis inhibitors [68]. They inhibit tumor angiogenesis and normalize tumor blood vessels [69]. Thus they increase the efficacy of chemotherapy agents by ensuring their delivery to the CRC. In AVF2107g trial, bevacizumab plus FOLFIRI showed improvement in overall survival (20.3 vs. 15.6 months) when given to patients with metastatic CRC [70]. The anti-EGFR agents showed improved survival in stage IV CRC and this benefit was seen only in KRAS wild type CRC [71]. Fifteen percent to $20 \%$ of stage II and stage III CRC are MMR-deficient (dMMR) or microsatellite instability-high (MSI-H) and carry a better prognosis than proficient mismatch repair (pMMR) or microsatellite stable (MSS) CRC, whereas 3.5\% of stage IV CRC are dMMR or MSI-H and are associated with a bad prognosis $[72,73]$. In dMMR or MSI-H CRC, there is an upregulation of checkpoint inhibitory proteins: PD1 (programmed cell death protein 1), PDL1 (programmed cell death protein ligand 1), CTLA-4 (cytotoxic T lymphocyte-associated antigen 4), LAG3 (lymphocyte activation gene-3 protein) and 
Table 6. Treatment of Different Stages of CRC

\begin{tabular}{ll}
\hline Stages of CRC & Treatment modalities \\
\hline Stage 1 & Endoscopic resection of pedunculated malignant polyp or surgical resection of tumor and local lymph nodes. \\
Stage 2 & Surgery alone. Adjuvant chemotherapy only in presence of high risk features. \\
Stage 3 & Surgery plus adjuvant chemotherapy. \\
Stage 4 & $\begin{array}{l}\text { Chemotherapy, biologic targeted therapy, immunotherapy, palliative surgery, radiotherapy, radiofrequency ablation and } \\
\text { colonic stenting. }\end{array}$ \\
\hline
\end{tabular}

CRC: colorectal cancer.

IDO (indoleamine 2,3-dioxygenase) [74]. Recently checkpoint inhibitors have been found to be helpful in patients with dMMR or MSI-H CRC. Overman et al found a durable clinical benefit in patients with dMMR or MSI-H metastatic CRC when they were treated with nivolumab plus ipilimumab [75]. PD1 inhibitors pembrolizumab and nivolumab are approved by the FDA for the treatment of dMMR or MSI-H metastatic CRC.

Palliative surgery is generally offered in the setting of colorectal obstruction and bleeding [76]. Colonic stent is also placed in the palliative setting of colonic obstruction. It has more than $90 \%$ technical success of deployment and relief of obstruction. Palliative stenting can avoid major surgery and shorten hospital stay [77]. In a subset of patients with CRC and isolated liver metastasis, if surgical resection is possible before or after chemotherapy, patient's longevity can be prolonged. Positron emission tomography (PET)/CT imaging can detect small intrahepatic and extrahepatic metastasis. In a study done by Fernandez et al, fluoro-2-deoxy-D-glucose-PET (FDG-PET) was done prior to surgical resection of isolated hepatic metastasis, and the 5-year survival rate of patients was $58 \%$ [78]. Other methods of treatment of liver metastasis include radiofrequency ablation, transarterial chemoembolization (TACE), hepatic intra-arterial chemotherapy infusion, radioembolization, external beam radiation and stereotactic radiation [79]. But surgery is the best treatment modality and relapse-free survival is much prolonged after surgery. The treatments of different stages of CRC are outlined in Table 6.

\section{Ongoing Research}

In the National Cancer Institute (NCI), many clinical trials are on-going for early detection, prevention and management of CRC. These include blood DNA test to detect CRC, immunotherapy in Lynch syndrome and MSI-H metastatic CRC, cancer vaccines to stimulate patient's immune system, hyperthermic intraperitoneal chemotherapy for better contact of cancer cells to chemotherapy [80].

\section{Conclusion}

Although the incidence and mortality of CRC have decreased by adopting the screening colonoscopy program, $\mathrm{CRC}$ is still the second most common cause of cancer-related death among all cancers affecting men and women in USA [81]. To reach the target of screening $80 \%$ of the eligible US population by 2024, 11 to 13 million colonoscopies would need to be performed annually. Appropriate measures should be taken to improve the ADR. The screening protocols recommended for average-risk and high-risk individuals for CRC should be followed. Malignant polyps should be managed appropriately by endoscopic treatment or segmental resection. Among all patients with CRC, $20-25 \%$ of patients have metastatic disease. Treatment should be chosen according to the extent of metastasis, KRAS mutation and microsatellite stability status of CRC. CRC should be managed by a multidisciplinary team which includes primary care physicians, gastroenterologists, surgeons, medical oncologists, interventional radiologists, radiation oncologists and palliative care team.

\section{Acknowledgments}

None to declare.

\section{Financial Disclosure}

None to declare.

\section{Conflict of Interest}

None to declare.

\section{Author Contributions}

Monjur Ahmed solely contributed to this article.

\section{References}

1. Marley AR, Nan H. Epidemiology of colorectal cancer. Int J Mol Epidemiol Genet. 2016;7(3):105-114

2. https://www.who.int/news-room/fact-sheets/detail/cancer.

3. Siegel RL, Miller KD, Jemal A. Cancer statistics, 2019. CA Cancer J Clin. 2019;69(1):7-34.

4. Cronin KA, Lake AJ, Scott S, Sherman RL, Noone AM, Howlader N, Henley SJ, et al. Annual Report to the Na- 
tion on the Status of Cancer, part I: National cancer statistics. Cancer. 2018;124(13):2785-2800.

5. Hadjipetrou A, Anyfantakis D, Galanakis CG, Kastanakis M, Kastanakis S. Colorectal cancer, screening and primary care: A mini literature review. World J Gastroenterol. 2017;23(33):6049-6058.

6. Weitz J, Knaebel HP, Buchler MW. [Sporadic and hereditary colorectal cancer. Pathogenetically different with different therapeutic indications]. Chirurg. 2003;74(8):717725.

7. Singh KE, Taylor TH, Pan CG, Stamos MJ, Zell JA. Colorectal Cancer Incidence Among Young Adults in California. J Adolesc Young Adult Oncol. 2014;3(4):176184.

8. Mork ME, You YN, Ying J, Bannon SA, Lynch PM, Rodriguez-Bigas MA, Vilar E. High Prevalence of Hereditary Cancer Syndromes in Adolescents and Young Adults With Colorectal Cancer. J Clin Oncol. 2015;33(31):35443549 .

9. Rex DK, Boland CR, Dominitz JA, Giardiello FM, Johnson DA, Kaltenbach T, Levin TR, et al. Colorectal cancer screening: Recommendations for physicians and patients from the U.S. Multi-Society Task Force on Colorectal Cancer. Gastrointest Endosc. 2017;86(1):18-33.

10. Qaseem A, Crandall CJ, Mustafa RA, Hicks LA, Wilt TJ, Clinical Guidelines Committee of the American College of P. Screening for Colorectal Cancer in Asymptomatic Average-Risk Adults: A Guidance Statement From the American College of Physicians. Ann Intern Med. 2019;171(9):643-654.

11. Wolf AMD, Fontham ETH, Church TR, Flowers CR, Guerra CE, LaMonte SJ, Etzioni R, et al. Colorectal cancer screening for average-risk adults: 2018 guideline update from the American Cancer Society. CA Cancer J Clin. 2018;68(4):250-281.

12. American Cancer Society Guideline for Colorectal Cancer. www.cancer.org, detection-diagnosis-staging, acsrecommendations.

13. Rivero-Sanchez L, Grau J, Auge JM, Moreno L, Pozo A, Serradesanferm A, Diaz M, et al. Colorectal cancer after negative colonoscopy in fecal immunochemical testpositive participants from a colorectal cancer screening program. Endosc Int Open. 2018;6(9):E1140-E1148.

14. Pasha SF. Applications of Colon Capsule Endoscopy. Curr Gastroenterol Rep. 2018;20(5):22.

15. Nian J, Sun X, Ming S, Yan C, Ma Y, Feng Y, Yang L, et al. Diagnostic Accuracy of Methylated SEPT9 for Blood-based Colorectal Cancer Detection: A Systematic Review and Meta-Analysis. Clin Transl Gastroenterol. 2017;8(1):e216.

16. Adler J, Robertson DJ. Interval Colorectal Cancer After Colonoscopy: Exploring Explanations and Solutions. Am J Gastroenterol. 2015;110(12):1657-1664; quiz 1665.

17. Samadder NJ, Curtin K, Tuohy TM, Pappas L, Boucher K, Provenzale D, Rowe KG, et al. Characteristics of missed or interval colorectal cancer and patient survival: a population-based study. Gastroenterology. 2014;146(4):950960 .

18. Ouyang DL, Chen JJ, Getzenberg RH, Schoen RE. Non- invasive testing for colorectal cancer: a review. Am J Gastroenterol. 2005;100(6):1393-1403.

19. Imperiale TF, Ransohoff DF, Itzkowitz SH, Turnbull BA, Ross ME, Colorectal Cancer Study G. Fecal DNA versus fecal occult blood for colorectal-cancer screening in an average-risk population. N Engl J Med. 2004;351(26):2704-2714.

20. Schoen RE, Pinsky PF, Weissfeld JL, Yokochi LA, Church T, Laiyemo AO, Bresalier R, et al. Colorectalcancer incidence and mortality with screening flexible sigmoidoscopy. N Engl J Med. 2012;366(25):2345-2357.

21. Ransohoff DF. How much does colonoscopy reduce colon cancer mortality? Ann Intern Med. 2009;150(1):5052.

22. Doubeni CA, Corley DA, Quinn VP, Jensen CD, Zauber AG, Goodman M, Johnson JR, et al. Effectiveness of screening colonoscopy in reducing the risk of death from right and left colon cancer: a large community-based study. Gut. 2018;67(2):291-298.

23. Stewart RJ, Stewart AW, Turnbull PR, Isbister WH. Sex differences in subsite incidence of large-bowel cancer. Dis Colon Rectum. 1983;26(10):658-660.

24. Schub R, Steinheber FU. Rightward shift of colon cancer. A feature of the aging gut. J Clin Gastroenterol. 1986;8(6):630-634.

25. Lee TJW, Nickerson C, Rees CJ, Rutter MD. Measuring the quality of screening colonoscopy: moving on from adenoma detection rate. Gut. 2011;60:A46.

26. Corley DA, Jensen CD, Marks AR, Zhao WK, Lee JK, Doubeni CA, Zauber AG, et al. Adenoma detection rate and risk of colorectal cancer and death. N Engl J Med. 2014;370(14):1298-1306.

27. Rex DK, Schoenfeld PS, Cohen J, Pike IM, Adler DG, Fennerty MB, Lieb JG, 2nd, et al. Quality indicators for colonoscopy. Am J Gastroenterol. 2015;110(1):72-90.

28. Deenadayalu VP, Chadalawada V, Rex DK. 170 degrees wide-angle colonoscope: effect on efficiency and miss rates. Am J Gastroenterol. 2004;99(11):2138-2142.

29. Committee AT, Konda V, Chauhan SS, Abu Dayyeh BK, Hwang JH, Komanduri S, Manfredi MA, et al. Endoscopes and devices to improve colon polyp detection. Gastrointest Endosc. 2015;81(5):1122-1129.

30. Joseph DA, Meester RG, Zauber AG, Manninen DL, Winges L, Dong FB, Peaker B, et al. Colorectal cancer screening: Estimated future colonoscopy need and current volume and capacity. Cancer. 2016;122(16):24792486.

31. Spadaccini M, Frazzoni L, Vanella G, East J, Radaelli F, Spada C, Fuccio L, et al. Efficacy and Tolerability of High- vs Low-Volume Split-Dose Bowel Cleansing Regimens for Colonoscopy: a Systematic Review and Metaanalysis. Clin Gastroenterol Hepatol. 2019.

32. Lai EJ, Calderwood AH, Doros G, Fix OK, Jacobson BC. The Boston bowel preparation scale: a valid and reliable instrument for colonoscopy-oriented research. Gastrointest Endosc. 2009;69(3 Pt 2):620-625.

33. Chaves Marques S. The Boston Bowel Preparation Scale: Is It Already Being Used? GE Port J Gastroenterol. 2018;25(5):219-221. 
34. Rex DK, Boland CR, Dominitz JA, Giardiello FM, Johnson DA, Kaltenbach T, Levin TR, et al. Colorectal Cancer Screening: Recommendations for Physicians and Patients From the U.S. Multi-Society Task Force on Colorectal Cancer. Gastroenterology. 2017;153(1):307-323.

35. https://ghr.nlm.nih.gov/condition/familial-adenomatouspolyposis.

36. Tudyka VN, Clark SK. Surgical treatment in familial adenomatous polyposis. Ann Gastroenterol. 2012;25(3):201206.

37. Oviedo RJ, Dixon BM, Sofiak CW. Emergency total proctocolectomy in an uninsured patient with Familial Adenomatous Polyposis Syndrome and acute lower gastrointestinal hemorrhage in a community hospital: A case report. Int J Surg Case Rep. 2016;26:166-169.

38. Parc YR, Olschwang S, Desaint B, Schmitt G, Parc RG, Tiret E. Familial adenomatous polyposis: prevalence of adenomas in the ileal pouch after restorative proctocolectomy. Ann Surg. 2001;233(3):360-364.

39. Hamilton SR, Bussey HJ, Mendelsohn G, Diamond MP, Pavlides G, Hutcheon D, Harbison M, et al. Ileal adenomas after colectomy in nine patients with adenomatous polyposis coli/Gardner's syndrome. Gastroenterology. 1979;77(6):1252-1257.

40. Knudsen AL, Bisgaard ML, Bulow S. Attenuated familial adenomatous polyposis (AFAP). A review of the literature. Fam Cancer. 2003;2(1):43-55.

41. Rex DK, Johnson DA, Anderson JC, Schoenfeld PS, Burke CA, Inadomi JM, American College of G. American College of Gastroenterology guidelines for colorectal cancer screening 2009 [corrected]. Am J Gastroenterol. 2009;104(3):739-750.

42. Rosty C, Hewett DG, Brown IS, Leggett BA, Whitehall VL. Serrated polyps of the large intestine: current understanding of diagnosis, pathogenesis, and clinical management. J Gastroenterol. 2013;48(3):287-302.

43. Boparai KS, Mathus-Vliegen EM, Koornstra JJ, Nagengast FM, van Leerdam M, van Noesel CJ, Houben M, et al. Increased colorectal cancer risk during follow-up in patients with hyperplastic polyposis syndrome: a multicentre cohort study. Gut. 2010;59(8):1094-1100.

44. Lieberman DA, Rex DK, Winawer SJ, Giardiello FM, Johnson DA, Levin TR. Guidelines for colonoscopy surveillance after screening and polypectomy: a consensus update by the US Multi-Society Task Force on Colorectal Cancer. Gastroenterology. 2012;143(3):844-857.

45. Mattar MC, Lough D, Pishvaian MJ, Charabaty A. Current management of inflammatory bowel disease and colorectal cancer. Gastrointest Cancer Res. 2011;4(2):5361.

46. Itzkowitz SH, Yio X. Inflammation and cancer IV. Colorectal cancer in inflammatory bowel disease: the role of inflammation. Am J Physiol Gastrointest Liver Physiol. 2004;287(1):G7-17.

47. Ekbom A, Helmick C, Zack M, Adami HO. Increased risk of large-bowel cancer in Crohn's disease with colonic involvement. Lancet. 1990;336(8711):357-359.

48. Farraye FA, Odze RD, Eaden J, Itzkowitz SH. AGA technical review on the diagnosis and management of colo- rectal neoplasia in inflammatory bowel disease. Gastroenterology. 2010;138(2):746-774; quiz e712-743.

49. Dulai PS, Sandborn WJ, Gupta S. Colorectal Cancer and Dysplasia in Inflammatory Bowel Disease: A Review of Disease Epidemiology, Pathophysiology, and Management. Cancer Prev Res (Phila). 2016;9(12):887-894.

50. Laine L, Kaltenbach T, Barkun A, McQuaid KR, Subramanian V, Soetikno R, Panel SGD. SCENIC international consensus statement on surveillance and management of dysplasia in inflammatory bowel disease. Gastrointest Endosc. 2015;81(3):489-501 e426.

51. Hurlstone DP, Sanders DS, Lobo AJ, McAlindon ME, Cross SS. Indigo carmine-assisted high-magnification chromoscopic colonoscopy for the detection and characterisation of intraepithelial neoplasia in ulcerative colitis: a prospective evaluation. Endoscopy. 2005;37(12):11861192.

52. Kiesslich R, Fritsch J, Holtmann M, Koehler HH, Stolte M, Kanzler S, Nafe B, et al. Methylene blue-aided chromoendoscopy for the detection of intraepithelial neoplasia and colon cancer in ulcerative colitis. Gastroenterology. 2003;124(4):880-888.

53. Jass JR. Pathogenesis of colorectal cancer. Surg Clin North Am. 2002;82(5):891-904.

54. Bolocan A, Ion D, Stoian RV, Serban MB. Map syndrome (MYH Associated Polyposis) colorectal cancer, etiopathological connections. J Med Life. 2011;4(1):109-111.

55. Dinu D, Dobre M, Panaitescu E, Birla R, Iosif C, Hoara $\mathrm{P}$, Caragui A, et al. Prognostic significance of KRAS gene mutations in colorectal cancer-preliminary study. J Med Life. 2014;7(4):581-587.

56. Liu B, Nicolaides NC, Markowitz S, Willson JK, Parsons RE, Jen J, Papadopolous N, et al. Mismatch repair gene defects in sporadic colorectal cancers with microsatellite instability. Nat Genet. 1995;9(1):48-55.

57. Barras D. BRAF Mutation in Colorectal Cancer: An Update. Biomark Cancer. 2015;7(Suppl 1):9-12.

58. Weisenberger DJ, Siegmund KD, Campan M, Young J, Long TI, Faasse MA, Kang GH, et al. CpG island methylator phenotype underlies sporadic microsatellite instability and is tightly associated with BRAF mutation in colorectal cancer. Nat Genet. 2006;38(7):787-793.

59. Orsenigo E, Gasparini G, Carlucci M. Clinicopathological Factors Influencing Lymph Node Yield in Colorectal Cancer: A Retrospective Study. Gastroenterol Res Pract. 2019;2019:5197914.

60. Bujanda L, Cosme A, Gil I, Arenas-Mirave JI. Malignant colorectal polyps. World J Gastroenterol. 2010;16(25):3103-3111.

61. Aarons CB, Shanmugan S, Bleier JI. Management of malignant colon polyps: current status and controversies. World J Gastroenterol. 2014;20(43):16178-16183.

62. Nivatvongs S, Rojanasakul A, Reiman HM, Dozois RR, Wolff BG, Pemberton JH, Beart RW, Jr., et al. The risk of lymph node metastasis in colorectal polyps with invasive adenocarcinoma. Dis Colon Rectum. 1991;34(4):323328.

63. Nascimbeni R, Burgart LJ, Nivatvongs S, Larson DR. Risk of lymph node metastasis in T1 carcinoma of the co- 
lon and rectum. Dis Colon Rectum. 2002;45(2):200-206.

64. Labianca R, Nordlinger B, Beretta GD, Mosconi S, Mandala M, Cervantes A, Arnold D, et al. Early colon cancer: ESMO Clinical Practice Guidelines for diagnosis, treatment and follow-up. Ann Oncol. 2013;24 Suppl 6:vi6472.

65. Lee YS, Kim HC, Jung KO, Cho YB, Yun SH, Lee WY, Chun HK. Oncologic Outcomes of Stage IIIA Colon Cancer for Different Chemotherapeutic Regimens. J Korean Soc Coloproctol. 2012;28(5):259-264.

66. Kye BH, Cho HM. Overview of radiation therapy for treating rectal cancer. Ann Coloproctol. 2014;30(4):165174.

67. Benson AB, 3rd, Venook AP, Cederquist L, Chan E, Chen YJ, Cooper HS, Deming D, et al. Colon Cancer, Version 1.2017, NCCN Clinical Practice Guidelines in Oncology. J Natl Compr Canc Netw. 2017;15(3):370-398.

68. Ohhara Y, Fukuda N, Takeuchi S, Honma R, Shimizu Y, Kinoshita I, Dosaka-Akita H. Role of targeted therapy in metastatic colorectal cancer. World J Gastrointest Oncol. 2016;8(9):642-655.

69. Cunningham D, Humblet Y, Siena S, Khayat D, Bleiberg H, Santoro A, Bets D, et al. Cetuximab monotherapy and cetuximab plus irinotecan in irinotecan-refractory metastatic colorectal cancer. N Engl J Med. 2004;351(4):337345.

70. Hurwitz H, Fehrenbacher L, Novotny W, Cartwright T, Hainsworth J, Heim W, Berlin J, et al. Bevacizumab plus irinotecan, fluorouracil, and leucovorin for metastatic colorectal cancer. N Engl J Med. 2004;350(23):2335-2342.

71. Van Cutsem E, Lenz HJ, Kohne CH, Heinemann V, Tejpar $\mathrm{S}$, Melezinek I, Beier F, et al. Fluorouracil, leucovorin, and irinotecan plus cetuximab treatment and RAS mutations in colorectal cancer. J Clin Oncol. 2015;33(7):692700 .

72. Colle R, Cohen R, Cochereau D, Duval A, Lascols O, Lopez-Trabada D, Afchain P, et al. Immunotherapy and patients treated for cancer with microsatellite instability. Bull Cancer. 2017;104(1):42-51.

73. Koopman M, Kortman GA, Mekenkamp L, Ligtenberg MJ, Hoogerbrugge N, Antonini NF, Punt CJ, et al. Defi- cient mismatch repair system in patients with sporadic advanced colorectal cancer. Br J Cancer. 2009;100(2):266273.

74. Llosa NJ, Cruise M, Tam A, Wicks EC, Hechenbleikner EM, Taube JM, Blosser RL, et al. The vigorous immune microenvironment of microsatellite instable colon cancer is balanced by multiple counter-inhibitory checkpoints. Cancer Discov. 2015;5(1):43-51.

75. Overman MJ, Lonardi S, Wong KYM, Lenz HJ, Gelsomino F, Aglietta M, Morse MA, et al. Durable Clinical Benefit With Nivolumab Plus Ipilimumab in DNA Mismatch Repair-Deficient/Microsatellite Instability-High Metastatic Colorectal Cancer. J Clin Oncol. 2018;36(8):773779.

76. Costi R, Leonardi F, Zanoni D, Violi V, Roncoroni L. Palliative care and end-stage colorectal cancer management: the surgeon meets the oncologist. World J Gastroenterol. 2014;20(24):7602-7621.

77. Borowiec AM, Wang CS, Yong E, Law C, Coburn N, Sutradhar R, Baxter N, et al. Colonic Stents for Colorectal Cancer Are Seldom Used and Mainly for Palliation of Obstruction: A Population-Based Study. Can J Gastroenterol Hepatol. 2016;2016:1945172.

78. Fernandez FG, Drebin JA, Linehan DC, Dehdashti F, Siegel BA, Strasberg SM. Five-year survival after resection of hepatic metastases from colorectal cancer in patients screened by positron emission tomography with F-18 fluorodeoxyglucose (FDG-PET). Ann Surg. 2004;240(3):438-447; discussion 447-450.

79. Liapi E, Geschwind JF. Transcatheter arterial chemoembolization for liver cancer: is it time to distinguish conventional from drug-eluting chemoembolization? Cardiovasc Intervent Radiol. 2011;34(1):37-49.

80. Advances in Colorectal Cancer Research. www.cancer. gov, types, colorectal, research.

81. U.S. Cancer Statistics Working Group. United States Cancer Statis- tics: 1999-2012 Incidence and Mortality Web-based Report. Atlanta: U.S. Department of Health and Human Services, Centers for Disease Control and Prevention and National Cancer Institute; 2015. Available at: www.cdc.gov/uscs. 